\title{
Evaluation of Physical and Framework Condition of Administrative Buildings in Order to Crisis Management in 5th Sector Isfahan City
}

\author{
Masoud Taghvaei (Corresponding Author) \\ Professor of Geography and Urban Planning \\ University of Isfahan \\ Isfahan, Iran \\ E-mail: m.taghvaei@geo.ui.ac.ir \\ Neda Rahmani \\ MA of Ggeography and Urban Planning \\ University of Isfahan \\ Isfahan, Iran \\ E-mail: nrahmani77@yahoo.com \\ Mahtab Taghvaei \\ Civil Engineer \\ E-mail: mahtabtaghvaei@gmail.com
}

Received: August 6, 2015 Accepted: November 25, 2015 Published: December 10, 2015

doi:10.5296/ijrd.v3i1.8147 URL: http://dx.doi.org/10.5296/ijrd.v3i1.8147

\begin{abstract}
Natural disasters have always existed during the life of earth. There is no place safe against natural disasters and crises. Therefore, communities were always looking for solutions to reducing damages and losses of Supervene incidents. One of the most fundamental human actions to decreasing losses of crisis incidence is "crisis management". As an important element, administrative units can play an important role during crisis in cities. These units
\end{abstract}


can be used in management, organizing rescue affairs, storage, habitation and shelter of victims. In this research, physical and framework condition of administrative buildings in $5^{\text {th }}$ sector of Isfahan city is evaluated. Heretofore, there is no study on evaluating physical and framework condition of administrative buildings in Isfahan city. This research is descriptive-analytic and survey and required information are gathered in five indicators using questionnaire through field studies. This information is evaluated and weighted using AHP method. The results indicated that among evaluated administrative centers, 15-code office with weight of $121 \%$ had the most vulnerability and 14-code office with weight of $0.21 \%$ had the lowest vulnerability.

Keywords: Planning, Physical and framework, Crisis management, Isfahan city

\section{Introduction}

Human habitation had a civilizing role in historical process of communities' development and in this process, cities as the best level of habitation were the focus of playing this role (Esmailpour, 2010, p. 96). Iran is known as one of top ten phenomenal countries of the world. By locating on Alp-Himalaya earthquake belt, Iran experienced 130 earthquakes with 7.5 Richter or more during past centuries (Ghafory-Ashtiany, 1999, p. 4). Crisis management is a dynamic process in frame of evaluated actions and is conducted before (planning and preparation), during (assistance to victims and relief) and after crisis (rebuilding and repairing) (Darbek, 1990, p. 23). One of the most important tasks of crisis management is reducing bad impacts of crisis, preparation and improving the conditions after the crisis (Rattien, 1990, p. 44). In such a way that crisis management is conducted based on a fundamental basis, analyzing risk of disaster prevention, preparation against it (before crisis incidence), emergency aids (during crisis incidence) and rebuilding (after crisis incidence) (Pourahmad et al., 2009, p. 2). Using observations after earthquake incidence all over the world, the concerned engineers concluded that the most buildings were ruined due to weakness among building elements such as wall and ceiling (Vakabayashi, 1995, p. 116).

Reinforcement, consistency and more attention to kind of materials and regulating some rules to controlling them and more monitoring by urban managers of urban management and planning are effective in reducing losses and financial or life damages (Faraji et al., 2009, p. 15). Administrative units as one of essential buildings and vital and important elements of the city have a chief role in its mobility and dynamicity. It means that administrative buildings, which are responsible for management, rescue issues organizing, warehousing, settlement and take caring of victims, lose their implementation as a unit with defined tasks due to damage and actually, management system of the city will be damaged and paralyzed; it results in delaying normalization operation after the crisis and doubles losses (Adampour, 2008 , p. 2). In such a way that nowadays, national strategies for protecting from vital infrastructures and key capitals of the country encompasses an important part of crisis management systems' divisions (John, 2004, p. 1). Isfahan city and its sub areas are placed in Zone of Sanandaj-Sirjan and it is always likely to occurrence of earthquake in this zone (Ambraseys \& Melville, 1982, p. 211). The present research is written according to importance of crisis management and its emphasis on physical and framework condition of 


\section{Macrothink}

administrative buildings in regards of evaluating vulnerability of these buildings during crisis incidences. The results of this research can be useful for urban managers and their planning and organizing and reforming administrative buildings of Isfahan city.

\section{Research Method}

Present research is descriptive-analytic type. The method of data gathering is survey and required information is gathered through providing and completing questionnaire. Statistical society is all offices of $5^{\text {th }}$ sector in Isfahan city which includes gas department‘water and wastewater, municipality and others. Data analysis is conducted using AHP and measures are evaluated and weighted.

\section{Research Domain}

$5^{\text {th }}$ sector of Isfahan municipality is one of 14 sectors of municipality which has area of 1549.2 hectares and by calculating military lands its area reaches to 2016.7 hectares. The population of this sector is 142000 persons and concentration (person per hectare) is equal to 70. $5^{\text {th }}$ sector is limited to Boustan Mellat avenue from north, to Shahid Agharebparast highway, to Chaharbagh Bala avenue and Hezarjerib avenue from east, to Habiballahi avenue from northwest and to Shahid Meisami avenue from west (information base of $5^{\text {th }}$ sector of Isfahan municipality, 2008, pp. 26-38).

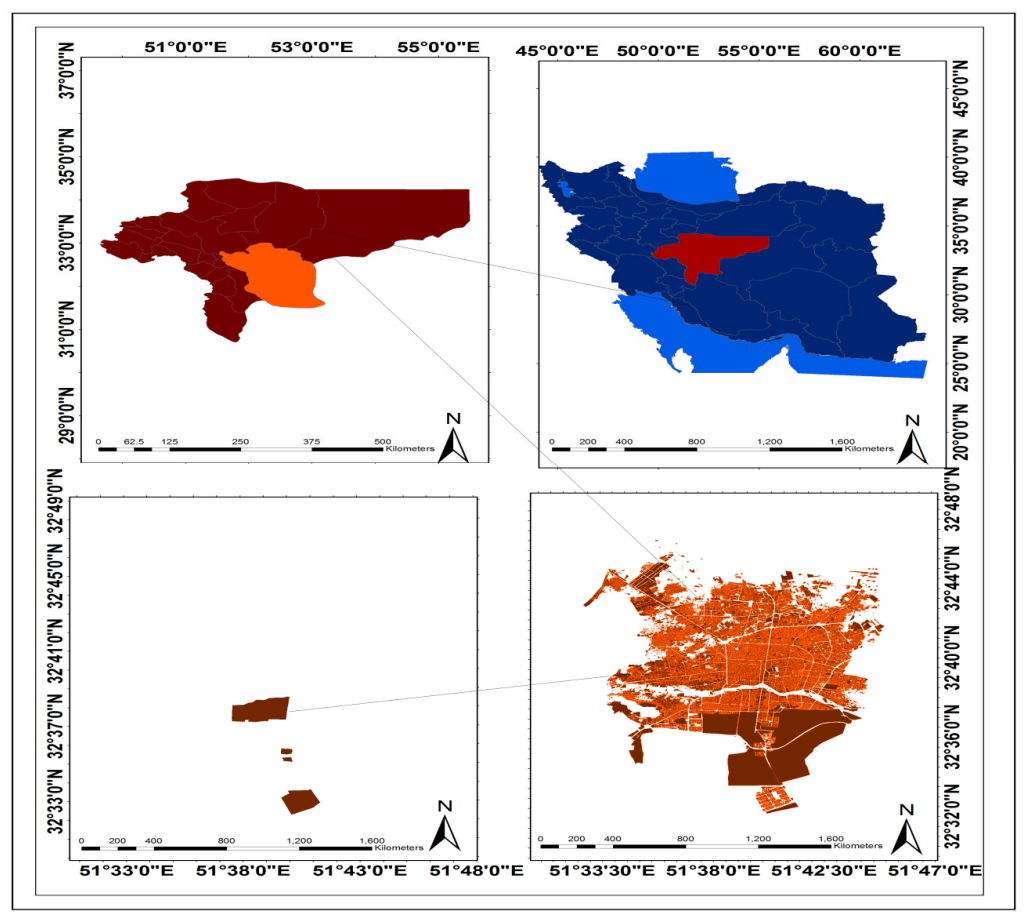

Figure 1. The map of study area, source authors 


\section{Definitions, Concepts and Theoretical Principles and Methods}

The concepts, which were considered in the research process for physical and framework, are including:

Foundation: foundation is beneath construction and a part of its surrounding soil which is affected by this construction and its loads. All foundations are designed to transferring loads of upper construction to the ground (Roshanzamir et al., 2003, p. 2). One of cases, which should be noticed in designing all constructions against earthquake, is foundation. Foundations of a building include those parts which touch with the ground and transfer framework loads of the building to it (Drump, 1977, p. 70).

Such as other buildings, foundation in administrative buildings is conducted based on the ground type, the soil resistance, method and system of foundation composing. As much as used materials in foundation are more resistance and using industrial methods, the foundation resistance will increase. Therefore, using concrete due to its industrial or half-industrial application method and using rock due to its resistance and stiffness are appropriate. The ground which administrative buildings are constructed on should be hard. Rock grounds are appropriate for making foundation of these buildings. As it possible, the used ground should be original without any past construction on it. The administrative buildings which are supposed to be build on high level grounds or places with underground water substrate, the level of underground water should be kept low as much as possible permanently or until the building has its quality using current methods in this regard. Digging channel surrounding the building is an appropriate method for it. We can organize around of administrative building by creating planted spaces and these channels can be used for irrigation of this space (Adampour, 2008, p. 35).

Skeleton: it is a steel skein made up by columns and beams that transfer all loads of the building to the foundation (Harris, 2006:1021). The most precious applied material is related to "iron skeleton" which has the lowest vulnerability among other materials (Ahadnejad et al, 2009:177).

Metal skeleton (steel constructions): the speed of implementing metal skeleton is more than other methods. In addition, this skeleton has adequate resistance in case of regarding calculation and implementation (Adampour, 2008:38).

Ceiling: upper level of room; it is usually has cover or decoration to hiding roof or bed of upper floor (Harris, 2006:210).

One of the main components of kinds of buildings is ceiling including concrete ceiling and its fundamental role is transferring horizontal and vertical forces of gravity loads and side forces such as loads of wind and earthquake to other backer components. According to conducted studies, old ceilings such as thatch ceilings and arches have a low resistance against incidents such as earthquakes. Gable roofs, joist blocks and concrete shell have relative resistance I building with one or two floors. It is better to use new systems of ceilings in administrative buildings to reducing damages of incidents. These types of ceiling show better resistance against incidents. The resistance of ceiling should be considered against fire as much as 
earthquake. For example, polystyrene ceilings are blazing rapidly. Therefore, it is better to use materials, which are standardized as fire-resistant. Using light plaster ceiling in those ceiling which in flammable materials are used can partly prevent fire transfer to these materials. In general, all cases, which are discussed in method of implanting ceiling, should be regarded in administrative buildings. Particularly, the type of used ceiling should be consistent with architecture of administrative buildings (Adampour, 2008, p. 41).

Wall: wall is a construction, which encloses a building or divides it. It usually has a continuous surface except where a door or window is applied in it (Harris, 2006, 1206).

The wall in an administrative building ensures three man purposes: identifying spaces, different types of protection and assisting to performing functional demands (Afrasiabi, 1986, p. 15). There are two type of wall in administrative buildings: interior and exterior walls. Each of them could be backer or non-backer. In administrative buildings, interior backer wall is used. These walls often close around of interior spaces, services, stairs and elevator. They are used as a resistance factor against horizontal forces and protection of stairs against fire. Implementing this type of wall is the most usual method to enforcing skeleton of the building (Adampour, 2008, p. 45).

Façade: façade is the most external part of the building. According that façade of building is in front of atmospheric factors, materials for façade should be chosen carefully, so constructed façade will be resistant to atmospheric factors and has necessary beauty and be consistent with side buildings (Kabbari, 1992:340). In administrative buildings, considering safety rules and regulations related to conducting façade is important especially in cities, which are prone to natural disasters. The importance of this matter is highlighted in cities having offices with high buildings and bad-situated, narrow and close crossovers due to barred ways and losing escape situation during incident. The application of beautiful facades with considering safety rules in administrative buildings and regarding principles of harmony with other urban constructions and environmental condition can reflect urbanization spirit in the city (Adampour, 2008, p. 49).

Hierarchic process technique: Saaty introduced analysis hierarchic process in 1971 as a spread analysis tool for modeling non-structured problems regarding political, economical, and social and management topics. This technique was fund based on paired comparison of bunch values of topics (Son Yu, 2002, 1970). The first stage in AHP is making hierarchic framework based on the question topic, which should show objectives, criteria, sub-criteria and their internal connection (Nekooee et al., 2011, p. 124).

This method is mostly applied to making decision in operative analysis with high risk in order to evaluating alternative plans or environmental effects in lower levels (Sonles, 2003, p. 295). Analytic hierarchic process needs paired comparison between options and these comparisons are conducted in frame of paired comparison matrix based on 9-part spectrum of Saaty in AHP technique (Bagheri Bodaghabadi, 2007, p. 107). The basis of AHP method is showing a hierarchy which helps to solving complex problem through simple processes. This procedure needs that criteria being analyzed uniformly (Mepal et al, 2010, p. 2). 


\section{Finding Analysis}

5.1 Determining Physical and Framework Condition of Administrative Buildings in Terms of Vulnerability during Crisis Incident

The objective of this research is leveling administrative centers in $5^{\text {th }}$ sector of Isfahan city in terms of their physical and framework vulnerability during crisis incident. Some criteria and sub - criteria are considered to evaluating physical and framework condition of administrative buildings in $5^{\text {th }}$ sector of Isfahan city. Their paired comparison will give the final weight of criteria, and then the centers will be evaluated. In the present research, sub - criteria also have some factors to evaluating centers, therefore, AHP model of the research has 4 levels and sub criteria of sub - criteria of level 2 are evaluated in level 3 and centers and options are evaluated in level 3. In table 1, the final weight of sub-criteria of sub-criteria is presented:

Table 1. Final weight of sub - criteria of sub-criteria

\begin{tabular}{|c|c|c|c|c|c|c|}
\hline Criterion & Weight & Sub-criterion & Weight & $\begin{array}{l}\text { Sub-criterion of } \\
\text { sub-criterion sub }\end{array}$ & ${ }^{f}$ Weight & The final weight \\
\hline \multirow{31}{*}{$\begin{array}{l}\text { Quality } \\
\text { Materials }\end{array}$} & \multirow{31}{*}{ of $_{0.485}$} & \multirow{4}{*}{$\begin{array}{l}\text { Material } \\
\text { foundation }\end{array}$} & \multirow{4}{*}{ of $_{0.513}$} & Concrete & 0.055 & 0.0136843 \\
\hline & & & & Stone and Concrete & 0.118 & 0.029359 \\
\hline & & & & Limestone & 0.262 & 0.0651869 \\
\hline & & & & Other & 0.565 & 0.1405748 \\
\hline & & \multirow{9}{*}{$\begin{array}{l}\text { Material } \\
\text { skeleton }\end{array}$} & \multirow{10}{*}{ of $_{0.261}$} & Concrete & 0.018 & 0.0022785 \\
\hline & & & & Cement block & 0.026 & 0.0032912 \\
\hline & & & & Steel & 0.041 & 0.00519 \\
\hline & & & & Brick and Iron & 0.063 & 0.0079479 \\
\hline & & & & All brick & 0.099 & 0.0125319 \\
\hline & & & & Brick and wood & 0.153 & 0.0193675 \\
\hline & & & & Stone and Wood & 0.237 & 0.0300006 \\
\hline & & & & Clay and Wood & 0.363 & 0.0459504 \\
\hline & & & & Concrete & 0.029 & 0.0018144 \\
\hline & & \multirow{5}{*}{\multicolumn{2}{|c|}{ Material of wall 0.129}} & Parochial & 0.049 & 0.0030657 \\
\hline & & & & Conventional bricks & 0.086 & 0.0053806 \\
\hline & & & & Grille Brick & 0.147 & 0.0091971 \\
\hline & & & & Stony & 0.254 & 0.0158915 \\
\hline & & & & Shingles & 0.435 & 0.0272158 \\
\hline & & \multirow{7}{*}{\multicolumn{2}{|c|}{ Material of roof 0.063}} & Joist Block & 0.021 & 0.0006417 \\
\hline & & & & Brick and Iron & 0.032 & 0.0009778 \\
\hline & & & & Ceiling Grid & 0.053 & 0.0016194 \\
\hline & & & & Wood & 0.146 & 0.004461 \\
\hline & & & & Wood and mud & 0.252 & 0.0076999 \\
\hline & & & & Shingles & 0.415 & 0.0126803 \\
\hline & & & & Gable roof & 0.080 & 0.0024444 \\
\hline & & \multirow{6}{*}{$\begin{array}{l}\text { Material } \\
\text { Façade }\end{array}$} & \multirow{6}{*}{${ }^{\text {of }} 0.033$} & Thatch & 0.027 & 0.0004321 \\
\hline & & & & Brick & 0.044 & 0.0007042 \\
\hline & & & & Stony & 0.155 & 0.0024808 \\
\hline & & & & Stone and Brick & 0.267 & 0.0042733 \\
\hline & & & & Glassy & 0.427 & 0.0068341 \\
\hline & & & & Other & 0.083 & 0.0013284 \\
\hline
\end{tabular}




\section{Macrothink}

After acquitting final weight of each sub - criterion of sub - criteria for administrative units in $5^{\text {th }}$ sector of Isfahan city, the total number of $5^{\text {th }}$ sector offices which is 17 is evaluated by forming $17 * 17$ matrix of each office respect to other offices in terms of physical and framework condition indicator and the weight of each office is obtained. Ultimately, the final analysis of each office in terms of foundation, skeleton, wall, façade and weight of each one is obtained according to calculations. The offices are identified using below codes: telecommunications: code 1. Municipality

building 1: code 2 . Municipality building 2: code 3 . Municipality building 3: code 4 . Water and wastewater office: code 5. Gas department: code 6. general governor: code 7. Education : code 8. Industry and mining organization: code 9. Economy and Finance issues: code 10. Housing Foundation of Islamic Revolution: code 11. Blood Donation Center: code 12. Social Security Organization: code 13. People record Office: code 14. Registry office: code 15. electricity issues: code 16 and fire fighting: code 17. This procedure is presented in figure (3):

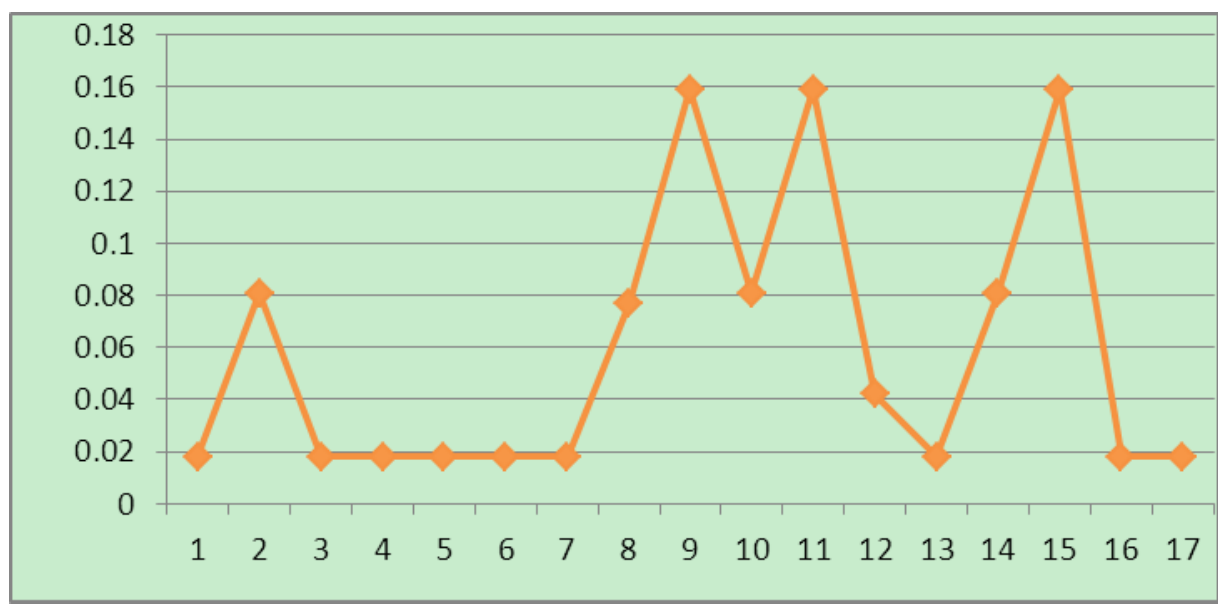

Figure 3. diagram of vulnerability of foundation in offices of $5^{\text {th }}$ sector in Isfahan city

According to obtained results and figure 3, it is obvious that among administrative centers, offices with code 15,11 , and 9 have the most vulnerability with weight $159 \%$ and other offices have low to moderate vulnerability with weight $0.77 \%$ to $0.81 \%$. 


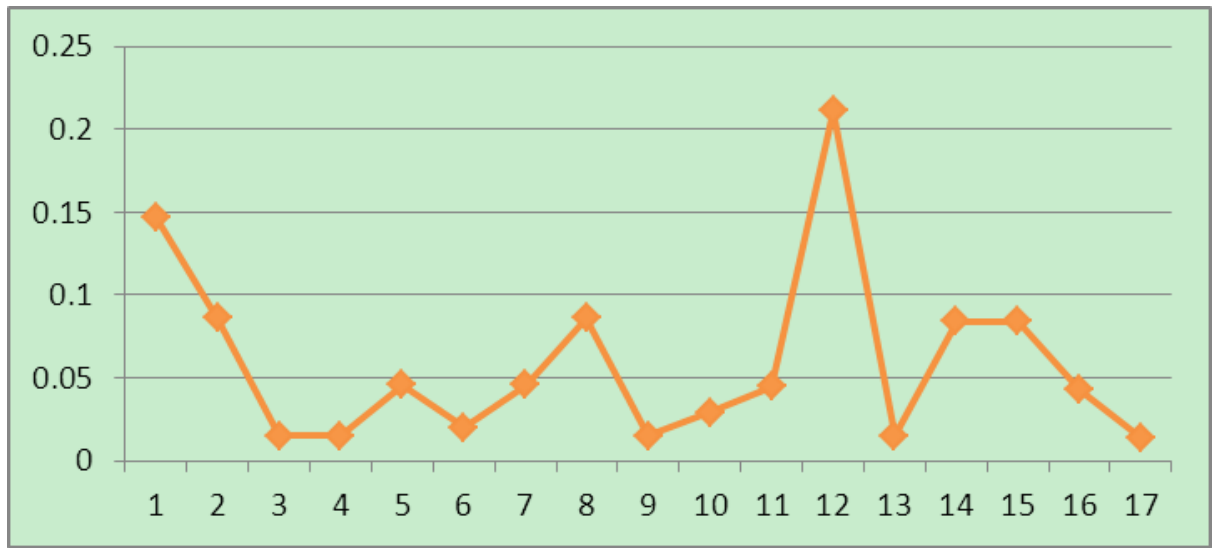

Figure 4. Diagram of vulnerability in skeleton of offices in $5^{\text {th }}$ sector of Isfahan city

According to obtained results and figure 4, it is obvious that in terms of skeleton criterion among administrative buildings, office with code 17 and $0.14 \%$ weight has the lowest vulnerability and office with code 12 and $211 \%$ weight has the highest vulnerability.

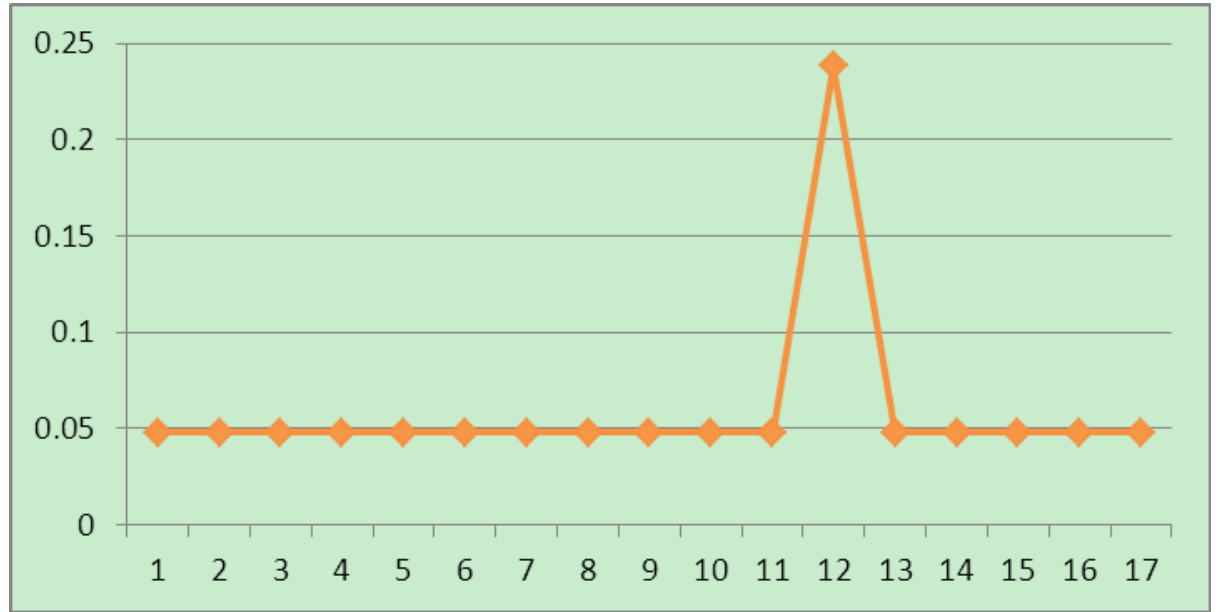

Figure 5. Diagram of vulnerability in walls of offices in $5^{\text {th }}$ sector of Isfahan city

According to obtained results and figure 5, in terms of wall criterion, the office with code 12 and $237 \%$ weight has a high vulnerability, but the other ones with the same weight of $0.48 \%$ have a low vulnerability. 


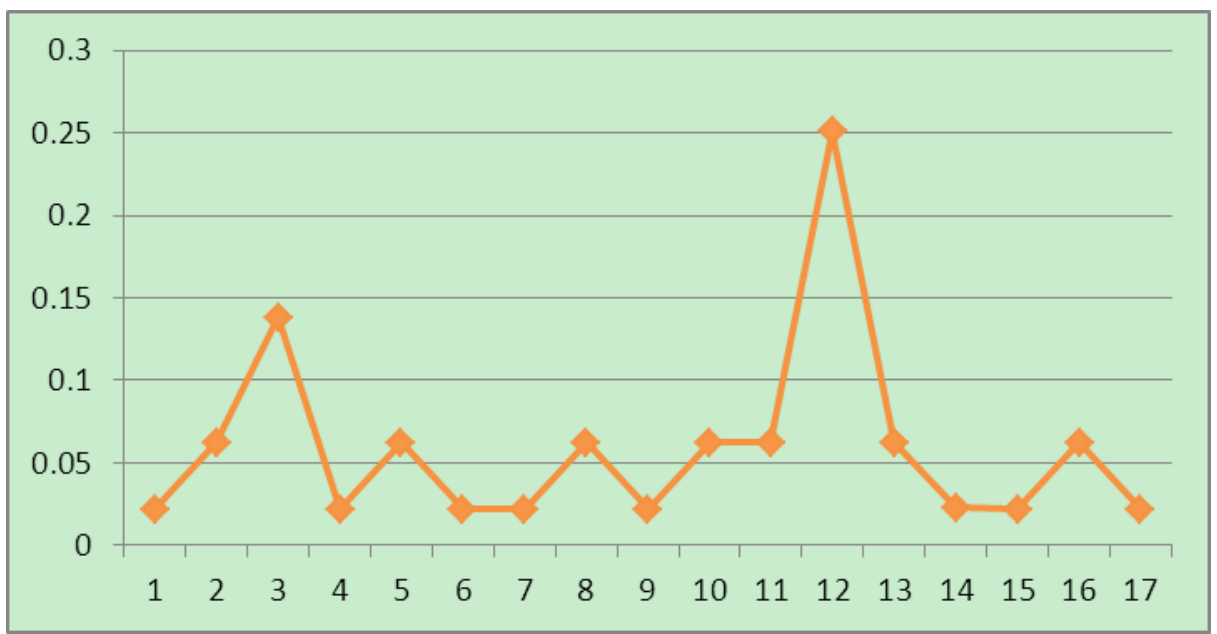

Figure 6. Diagram of vulnerability in ceiling of offices in $5^{\text {th }}$ sector of Isfahan city

According to obtained results and figure 6 , it is obvious that in terms of ceiling criterion among offices, the office with code 12 and $251 \%$ weight, the office with code 3 and $138 \%$ weight have the highest vulnerability and other offices have the lowest vulnerability with weight $0.22 \%$ and $0.62 \%$.

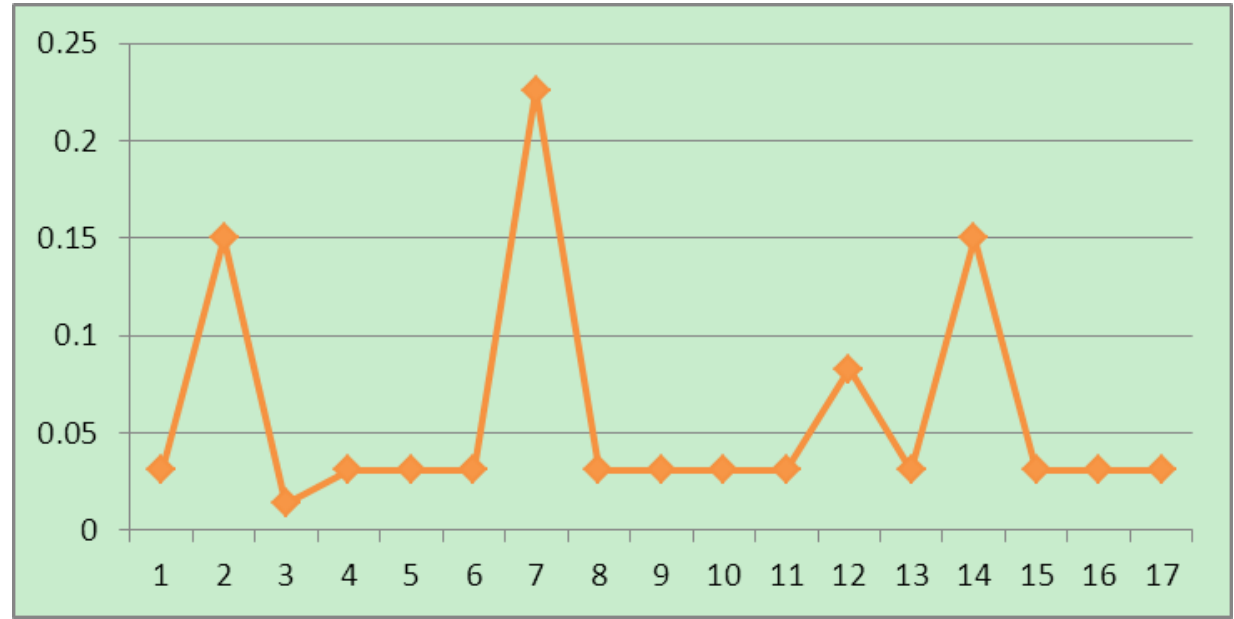

Figure 7. Diagram of vulnerability in façade of offices in $5^{\text {th }}$ sector of Isfahan city

According to obtained results and figure 7 , it is obvious that in terms of façade criterion among offices, the office with code 7 and weight $226 \%$ and the office with code 14 with weight $15 \%$ and the office with code 2 and weight $15 \%$ have the highest vulnerability and other offices have the lowest vulnerability with weight $0.31 \%$ to $0.83 \%$. 


\section{Macrothink}

International Journal of Regional Development

ISSN 2373-9851

2016, Vol. 3, No. 1

Table 2. Final scores of physical and framework condition of offices in $5^{\text {th }}$ sector of Isfahan city

\begin{tabular}{llll}
\hline Office code & Total scores & Office code & Total scores \\
\hline 1 & 051. & 10 & .063 \\
2 & 080. & 11 & .114 \\
3 & .026 & 12 & .111 \\
4 & 021. & 13 & .022 \\
5 & .030 & 14 & .077 \\
6 & .022 & 15 & .121 \\
7 & .033 & 16 & .029 \\
8 & .074 & 17 & .021 \\
9 & .105 & & \\
\hline
\end{tabular}

According to obtained results and Figure 8, it is obvious that in terms of general criterion for physical and framework condition among offices, the office with code 15 and weight $121 \%$ has the highest vulnerability and the office with code 4 and weight $0.21 \%$ has the lowest vulnerability.

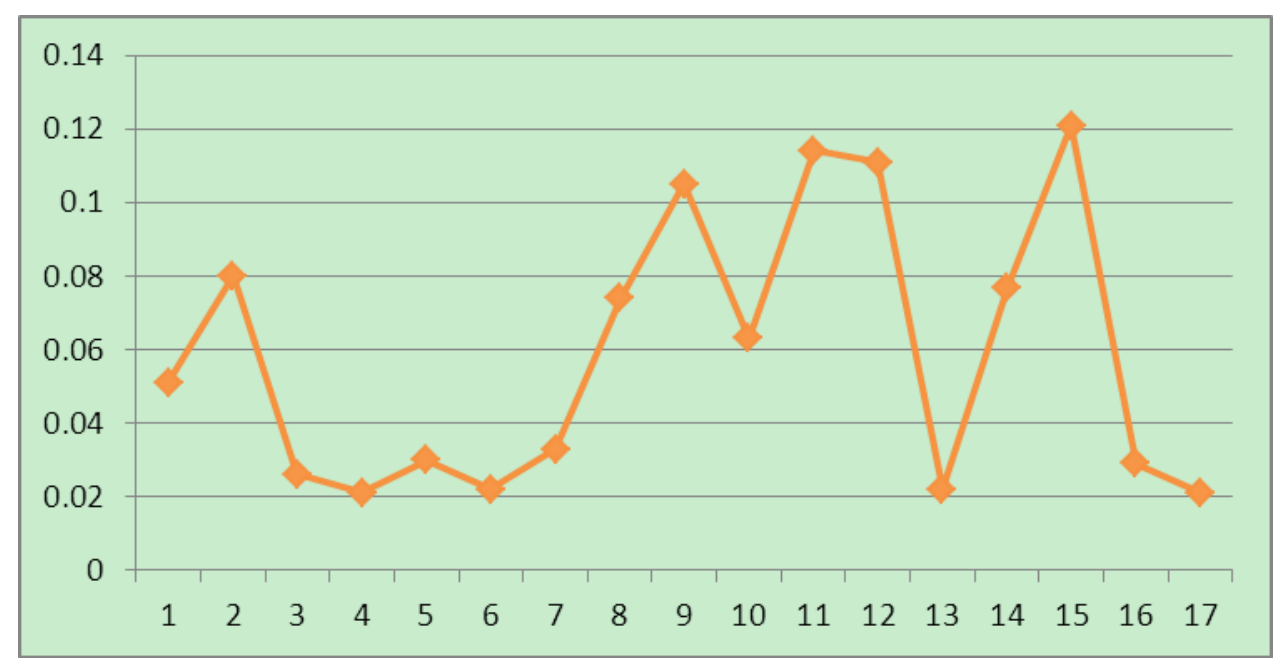

Figure 8. Diagram of vulnerability in physical and framework condition of $5^{\text {th }}$ sector in Isfahan city

\section{Conclusions and Research Recommendations}

Iran is located in an area, which is prone to earthquake; and place and time of natural disasters is supervened. Therefore, a comprehensive plan of crisis management in order to reducing risks and damages due to disaster incident is necessary and important. As a necessary construction, administrative units have a fundamental role in mobility and 
dynamicity of the city. This research is written according to importance of crisis management knowledge and its emphasis on physical and framework condition of administrative buildings of $5^{\text {th }}$ sector in Isfahan city in regard of evaluating vulnerability of these buildings during crisis incident. This research followed analyzing current physical and framework condition of administrative buildings in $5^{\text {th }}$ sector of Isfahan city and forecasting future condition in different sections needs precise and up-to-date information and data. Therefore, up to date data were gathered using questionnaire and field studies from administrative users in Isfahan city. Measures are evaluated and weighted using Saaty method and finally, following results were obtained:

Among administrative centers, offices with code 15, 11, and 9 have the most vulnerability with weight $159 \%$ and other offices have low to moderate vulnerability with weight $0.77 \%$ to $0.81 \%$.

In terms of skeleton criterion among administrative buildings, office with code 17 and $0.14 \%$ weight has the lowest vulnerability and office with code 12 and $211 \%$ weight has the highest vulnerability.

In terms of wall criterion, the office with code 12 and $237 \%$ weight has a high vulnerability, but the other ones with the same weight of $0.48 \%$ have a low vulnerability.

In terms of ceiling criterion among offices, the office with code 12 and $251 \%$ weight, the office with code 3 and 138\% weight have the highest vulnerability and other offices have the lowest vulnerability with weight $0.22 \%$ and $0.62 \%$.

In terms of façade criterion among offices, the office with code 7 and weight $226 \%$ and the office with code 14 with weight $15 \%$ and the office with code 2 and weight $15 \%$ have the highest vulnerability and other offices have the lowest vulnerability with weight $0.31 \%$ to $0.83 \%$.

In terms of general criterion for physical and framework condition among offices, the office with code 15 and weight $121 \%$ has the highest vulnerability and the office with code 4 and weight $0.21 \%$ has the lowest vulnerability.

The following recommendations are provided to improving physical and framework condition of offices in $5^{\text {th }}$ sector of Isfahan city:

-Controlling and monitoring constructions in the city that is recommended quickly in terms of time

-Preparing map of risky areas' zoning in terms of proximity to fault which is recommended quickly in terms of time

-Securing current construction and proper designing being-build constructions that is recommended quickly in terms of time

-Improving resistance of building of government and private companies that is recommended as a long-term project in terms of time 
-Promoting condition of constructing administrative units: in order to promoting condition of constructing administrative units we should pay more attention to local knowledge and materials and applying standard and resistant materials which are complied with new technologies to make resistant buildings and facing with lowest vulnerability during crisis incident. This is recommended as a long - term project in terms of time.

Modernization and reformation plans for administrative buildings would be conducted which is recommended as a long - term project in terms of time.

\section{References}

Adampour, E. (2008). An analysis of the architectural and urban office buildings, with emphasis on unexpected events in Chahar Mahal and Bakhtiari province. MS Thesis, University of Najaf Abad Azad.

Ahadnezhad, R. M. (2009). Modeling of vulnerability of urban buildings against earthquake using analytic hierarchy process in GIS Environment (Case study: Zanjan city). Journal of Geography and Development, 19.

Ambraseys, N. N., \& Melville, C. P. (1982). A history of Persian earthquake. Cambridge, Earth Science Series.

Bagheri, B. A., Amini Fskhvdy, A., \& Jesus, E. (2007). Salinity zoning to use the green environment by using AHP and principles of geostatistical techniques (on the island). Journal of Research, 22.

Darbak, T. E. (1990). Emergency Management: Strategies for maintaining Organizational Integrity.

Dramp, P. (1977). Foundations, translated by Kambiz Behnia. Tehran University Press.

Esmaeelpour, N. (2010). Evaluation of housing conditions in informal settlements and provide strategies for organizing them (Case Study: Yazd good quarter). Urban and Regional Studies and Research Journal, 1(4).

Faraji, A., \& Gharakhlou, M. (2009). Urban Earthquake Disaster Management (Case Study: Babol). Geography (Geographic Society's Journal), 8(25).

Ghafory-Ashtiany, M. (1999). Rescue Operation and Reconstructions in Iran, Disaster Prevention and Management, 8(1).

Harris, C. (2006). Anatomical Dictionary of Architecture and Construction. Translated by Mohammad Reza Afzali, M. Hashem Zadeh H. Tehran: Associated Press.

Isfahan County. (2008). Comparative Analysis of General Population and Housing Census 2006-1996 years Isfahan.

Johan, M., \& Paul, P. (2004). Critical Infrastructure and key assets: Defifition and Idenfinication.

Kebari, S. (1992). Components of Building and Construction. Vertical Press, sixth edition. 


\section{Macrothink}

International Journal of Regional Development ISSN 2373-9851 2016, Vol. 3, No. 1

Mepal, B., Yadavm, O. P., \& Murat, A. (2010). A fuzzy-AHP approach to prioritization of CS attributes in target planning for automotive product development. Expert System With Applications.

Nekooeezahra, M. K., \& Iman, F. (2011) Assessment and Prioritization Process (AHP), (A Case Study of Birjand, Iran). Journal of Applied Business and Economics, 12(4), 122-34.

Pourahmad, A., Lotfi, S., \& Faraji, A. (2009). Evaluation of Earthquake Disaster Prevention (Case Study: City of Babylon). Urban and Regional Studies and Research, 1(1).

Rattien, S. (1990). The Role of Media in Hazard Mitigation \& Disaster Management. Disaster Press.

Roshan, Z., Muhammad, A., \& Shokrani, H. (2003). Foundation Engineering. Isfahan, Institute of Brain Science Scholars.

Rukn Abadi, A. (1990). Topography and climate of the area and its impact on the landscape.

Sfyddashty, A. A. J. (1986). Discussion of space in office buildings. Publication No. 49, Tehran, Office of Technical Standards and Planning Organization.

Solnes, J. (2003). Environmental quality indexing of large industrial developnment alternatives using AHP. Environmental Impact Assessment Review, 23(8).

Son, Y. C. (2002). A GP-AHP method for solving group decisionmaking fuzzy AHP problems. Computer and Operations Research, (29), 1969-2001.

Vakabayashy, M. (1995). Earthquake resistant building design, architecture and translator Ali Mohamed F. divine orator. Publisher of the International Institute of Seismology and Earthquake Engineering, Tehran Printing.

\section{Copyright Disclaimer}

Copyright for this article is retained by the author(s), with first publication rights granted to the journal.

This is an open-access article distributed under the terms and conditions of the Creative Commons Attribution license (http://creativecommons.org/licenses/by/3.0/). 